\title{
Effect of cigarette smoking on subgingival bacteria in healthy subjects and patients with chronic periodontitis
}

\author{
Jumana A. Karasneh" ${ }^{1 *}$, Rola A. Al Habashneh ${ }^{2}$, Nour Aldain S. Marzouka ${ }^{3}$ and Martin H. Thornhill ${ }^{4}$
}

\begin{abstract}
Background: Cigarette smoking is known to increase the risk of periodontal destruction and developing chronic periodontitis (CP). It is also reported to affect the subgingival bacterial profile among CP patients. However, studies on the effect of smoking on the bacterial profile among healthy subjects are still limited. Therefore, the aim of this study was to investigate the impact of smoking on the subgingival bacterial profile in both healthy adults and CP patients.

Methods: Subgingival plaque samples were collected from CP patients (30 nonsmokers and 9 smokers) and healthy subjects (37 non-smokers and 18 smokers). Genomic DNA was extracted and 25 bacterial species were detected using PCR of 165 rRNA. Comparing smokers to non-smokers from each group was conducted using chi2 and binary logistic regression analysis.

Results: After correcting for confounding factors, the odds of having Slackia exigua, Selenomonas sputigena and Campylobacter rectus was higher among healthy smokers (ORadj $=10.1,6.62$ and 5.62 respectively). While for CP group, the highest odds were observed for Treponema amylovorum, Treponema medium, Slackia exigua and Treponema vincentii (ORadj $=20.7,7.97,6.37$ and 5.37 respectively) and the increase in Treponema amylovorum was statistically significant $(p=0.05)$.

Conclusion: Smoking affects the subgingival bacterial profile in healthy individuals and is responsible for the depletion of beneficial bacteria and the increase in periodontopathogenic bacteria. In the CP patient group, our study suggests that subgingival bacteria (particularly Treponema species) make a more substantial contribution in the etiology of CP among non-smokers. Further studies using a larger sample set and more sensitive and quantitative techniques (such as real -time PCR) are needed to enhance our understanding of the exact effect of smoking on subgingival biofilm.
\end{abstract}

Keywords: Bacteria, Cigarette smoking, Chronic periodontitis, Polymerase chain reaction, 16 S ribosomal RNA

\section{Background}

Periodontitis is a group of inflammatory diseases affecting the supporting tissues of the teeth. Periodontal diseases are classified as complex disorders where environmental, lifestyle and genetic factors contribute to their etiology [1]. The most important environmental factor is the diverse microbiota arranged in a biofilm [2] which acts as an initiator of periodontal destruction, while lifestyle factors, such

\footnotetext{
* Correspondence: jumana2003@yahoo.com

${ }^{1}$ Department of Oral Medicine \& Oral Surgery, Faculty of Dentistry, Jordan

University of Science \& Technology, Irbid, Jordan

Full list of author information is available at the end of the article
}

as smoking and oral hygiene habits, act as modifiers of disease presentation [3]. Cigarette smoking has been shown to be responsible for accelerated periodontal destruction and increased risk of periodontitis in young adults [4]. Based on epidemiological studies, smokers have more severe chronic periodontitis $(\mathrm{CP})$ than non-smokers [5] and the relationship is dose-dependent [6], both in terms of number of cigarettes smoked and number of years smoking [7]. It has been suggested that increased severity of periodontitis among smokers compared to non-smokers is, in part, induced by differences in the subgingival bacterial profile [8]. 
Reports on the effect of smoking on the composition of the subgingival microbiota are inconclusive; some studies report a minor effect [9] and some report no effect of smoking on the subgingival microbiota [10]. However, most studies report a significant difference in the subgingival microbiota between smokers and nonsmokers [8, 11-14]. These studies were all conducted on patients with periodontal disease. In contrast, studies on healthy individuals are limited with only one study investigating the effect of smoking on the subgingival microbiota of healthy young adults [15]. In order to determine the effect of smoking on subgingival bacteria, other confounding factors that would dilute or interfere with the effect of smoking, particularly those associated with periodontal disease, should be eliminated.

Therefore, the aim of the present study was to determine whether smoking affects the subgingival bacteria in healthy individuals. It also aimed to investigate if there is a difference in the subgingival microbiota between smoking induced periodontitis and periodontitis induced by factors other than smoking.

\section{Methods}

\section{Study groups}

The study was independently reviewed and approved by the Institutional Research Board (IRB) of Jordan University of Science and Technology (JUST). The purpose and methodology of the study, including possible future publication of clinical datasets, were fully explained to all participants or their parents if they were under the age of 18 years and their written consent was obtained before interviews, examinations and sample collection, complying with the tenets of the revised Declaration of Helsinki.

In total, 150 participants were enrolled in the study at the initial screening unit in the Dental Teaching Centre (DTC) of Jordan University of Science \& Technology (JUST). Demographic data and medical history were collected, and brief extraoral and intraoral clinical examinations were performed. Patients with clinically healthy gingiva were referred to the oral diagnosis clinic and those with suspected periodontal disease were referred to the periodontics clinic, both located in the DTC. Selection criteria were: systemically healthy; Jordanian; no periodontal treatment or antimicrobial therapy for at least 6 months before the examination; at least seven natural teeth/quadrant with no fixed or removable prosthesis. Any participants using long-term medications, receiving orthodontic treatment, under the age of 16 , or pregnant were excluded. Once in the designated clinic, supragingival plaque was scored and, when present, it was carefully removed. Teeth were isolated using cotton rolls, and subgingival plaque was collected prior to any periodontal examination by inserting a paper point for $30 \mathrm{~s}$ into the mesial sulcus of each posterior tooth apart from the third molar if present (16 sites in total). The clinical diagnosis was based on the 1999 Consensus Classification of Periodontal Diseases [16]. Four clinical variables were recorded for all participants: the periodontal pocket depth (PPD), clinical attachment loss (CAL), plaque index (PI) and gingival index (GI) [17]. The absence of periodontal disease was defined as the absence of sites with PPD of $\geq 4 \mathrm{~mm}$ in any tooth and confirmed by radiographic examination. Paper points contaminated with blood were not included as this might affect DNA quality, only points from non-bleeding sites were pooled together, placed in Eppendorf tubes and stored at $-20{ }^{\circ} \mathrm{C}$ for extraction of genomic DNA and analysis. Only participants who satisfied the inclusion criteria and had a clear-cut diagnosis were included in the study and DNA was extracted from plaque samples. In total a study population of 94 unrelated individuals: 30 nonsmoker CP cases (18-50 years), 9 current smoker CP cases (28-48 years), 37 non-smoker periodontally healthy subjects (17-53 years), and 18 current smoker periodontally healthy subjects (17-43 years).

\section{Molecular technique}

Samples were placed in $2 \mathrm{ml}$ phosphate-buffered saline (PBS) and incubated for $3 \mathrm{~h}$ at room temperature. Each sample was centrifuged at $5000 \times g$ for $10 \mathrm{~min}$ and the supernatants removed. Genomic DNA was then extracted from the pellets using QIAamp DNA Mini Kit (Qiagen $\mathrm{GmbH}$, Hilden, Germany) according to the manufacturer's instructions.

In the first amplification, the 16S rRNA genes were amplified by PCR with universal primers $27 \mathrm{~F}$ and 1492R [18]. The primer sequences were: 27 F, 5'-AGA GTT TGA TCC TGG CTC AG-3'; and 1492R, 5' -TAC GGG TAC CTT GTT ACG ACT T-3'. PCR was performed in $25 \mu \mathrm{l}$ volumes using $12.5 \mu \mathrm{l}$ of PCR master mix (Promega, USA), $6.5 \mu \mathrm{l}$ of nuclease free water, $1 \mu \mathrm{l}$ of forward and reverse primers and $5 \mu \mathrm{l}$ of DNA. Amplifications were performed using a PCR Thermal Cycler (Bio-RAD, USA) programed for $10 \mathrm{~min}$ at $95^{\circ} \mathrm{C}$ for initial heat activation, 35 cycles of $45 \mathrm{~s}$ at $95{ }^{\circ} \mathrm{C}$ for denaturation, $45 \mathrm{~s}$ at $60{ }^{\circ} \mathrm{C}$ for annealing, $45 \mathrm{~s}$ at $72{ }^{\circ} \mathrm{C}$ for extension, and $7 \mathrm{~min}$ at $72{ }^{\circ} \mathrm{C}$ for final extension. The size of the PCR product using the universal primers was $1505 \mathrm{bp}$.

The presence or absence of the bacteria was determined by the presence or absence of the PCR band resulting from using previously reported species-specific primers [19] on the first universal PCR product as a template after being checked on Primer-BLAST (www.ncbi.nlm.nih.gov/tools/primer-blast/). Primer sequences can be found in additional word document file (see Additional file 1). PCR mixtures were prepared using $5 \mu \mathrm{l}$ of the first PCR amplification mixture and $20 \mu \mathrm{l}$ of the reaction mixture containing $0.5 \mu \mathrm{l}$ of 
Table 1 Demographic, socioeconomic and clinical data for the study groups

\begin{tabular}{|c|c|c|c|c|}
\hline & \multicolumn{2}{|l|}{ Healthy } & \multicolumn{2}{|c|}{ Chronic periodontitis } \\
\hline & Non-smoker & Smoker & Non-smoker & Smoker \\
\hline & $N=37$ & $N=18$ & $N=30$ & $N=9$ \\
\hline \multicolumn{5}{|l|}{ Gender } \\
\hline Male (\%) & $14(37.8)$ & $16(88.9)$ & $5(16.7)$ & $7(77.8)$ \\
\hline Female (\%) & $23(62.2)$ & $2(11.1)$ & $25(83.3)$ & $2(22.2)$ \\
\hline$P$ value & $<0.0001$ & & $<0.0001$ & \\
\hline Age (mean $\pm S D$ ), years & $31.84 \pm 10.10$ & $26.94 \pm 8.39$ & $38.96 \pm 10.65$ & $40.63 \pm 6.72$ \\
\hline$P$ value & 0.065 & & 0.600 & \\
\hline \multicolumn{5}{|l|}{ Education level } \\
\hline$\geq$ University (\%) & $15(40.5)$ & $10(55.6)$ & $13(46.4)$ & $7(87.5)$ \\
\hline < University (\%) & $22(59.5)$ & $8(44.4)$ & $15(53.6)$ & $1(12.5)$ \\
\hline$P$ value & 0.294 & & 0.039 & \\
\hline \multicolumn{5}{|l|}{ Family income } \\
\hline Low income (\%) & $17(45.9)$ & $10(55.6)$ & $19(65.5)$ & $5(55.6)$ \\
\hline Middle income (\%) & $12(32.4)$ & $4(22.2)$ & $10(34.5)$ & $4(44.4)$ \\
\hline High income (\%) & $7(18.9)$ & $4(22.2)$ & $0(0.0)$ & $(0.0)$ \\
\hline$P$ value & 0.750 & & 0.699 & \\
\hline PPD (mean \pm SD), mm & $2.41 \pm 0.82$ & $1.87 \pm 0.64$ & $5.14 \pm 0.74$ & $4.75 \pm 0.89$ \\
\hline$P$ value & 0.017 & & 0.284 & \\
\hline CAL (mean $\pm S D), m m$ & $0.0 \pm 0.0$ & $0.0 \pm 0.0$ & $5.14 \pm 1.06$ & $4.88 \pm 0.84$ \\
\hline$P$ value & 1.000 & & 0.471 & \\
\hline PI (mean $\pm S D)$ & $1.41 \pm 0.50$ & $1.60 \pm 0.51$ & $2.31 \pm 0.54$ & $2.38 \pm 0.74$ \\
\hline$P$ value & 0.240 & & 0.823 & \\
\hline Gl (mean $\pm S D)$ & $1.47 \pm 0.62$ & $1.60 \pm 0.63$ & $2.31 \pm 0.54$ & $2.25 \pm 0.46$ \\
\hline$P$ value & 0.511 & & 0.758 & \\
\hline \multicolumn{5}{|l|}{ Smoking quantitiy } \\
\hline < 10 cig/day (\%) & - & $3(16.7)$ & - & $0(0.0)$ \\
\hline 10-20 cig/day (\%) & - & $11(61.1)$ & - & $7(77.8)$ \\
\hline > 20 cig/day (\%) & - & $4(22.2)$ & - & $2(22.2)$ \\
\hline \multicolumn{5}{|l|}{ Smoking duration } \\
\hline$<5$ years $(\%)$ & - & $4(22.2)$ & - & $2(22.2)$ \\
\hline $5-10$ years (\%) & - & $10(65.6)$ & - & $4(44.5)$ \\
\hline$>10$ years $(\%)$ & - & $4(22.2)$ & - & $3(33.3)$ \\
\hline
\end{tabular}

Significant $P$ values $\leq 0.05$ are shown in bold

species-specific primer, $13 \mu \mathrm{l}$ of PCR master mix (Promega, USA) and $6.5 \mu \mathrm{l}$ of nuclease free water. PCR amplification was performed in a PCR Thermal Cycler (Bio-RAD, USA) programed for $10 \mathrm{~min}$ at $95{ }^{\circ} \mathrm{C}$ for initial heat activation, 35 cycles of $1 \mathrm{~min}$ at $95^{\circ} \mathrm{C}$ for denaturation, $45 \mathrm{~s}$ at $55^{\circ} \mathrm{C}$ for annealing, $45 \mathrm{~s}$ at $72{ }^{\circ} \mathrm{C}$ for extension, and $7 \mathrm{~min}$ at $72{ }^{\circ} \mathrm{C}$ for final extension.

The PCR products were separated on $2 \%$ agarose gels stained with ethidium bromide and visualized under a UV light transilluminator. With each gel run, negative and positive control samples were run simultaneously.
In any case of uncertainty about the presence or absence of a bacteria-specific band, the PCR was repeated.

\section{Statistical analysis}

Continuous variables were presented using mean \pm SD and compared using the independent sample $t$-test, categorical variables were presented using frequencies and percentages, and were compared using Chi squared analysis. Binary logistic regression analysis was used to calculate the odds of having each bacterium in smokers compared to non-smokers for both healthy and CP 


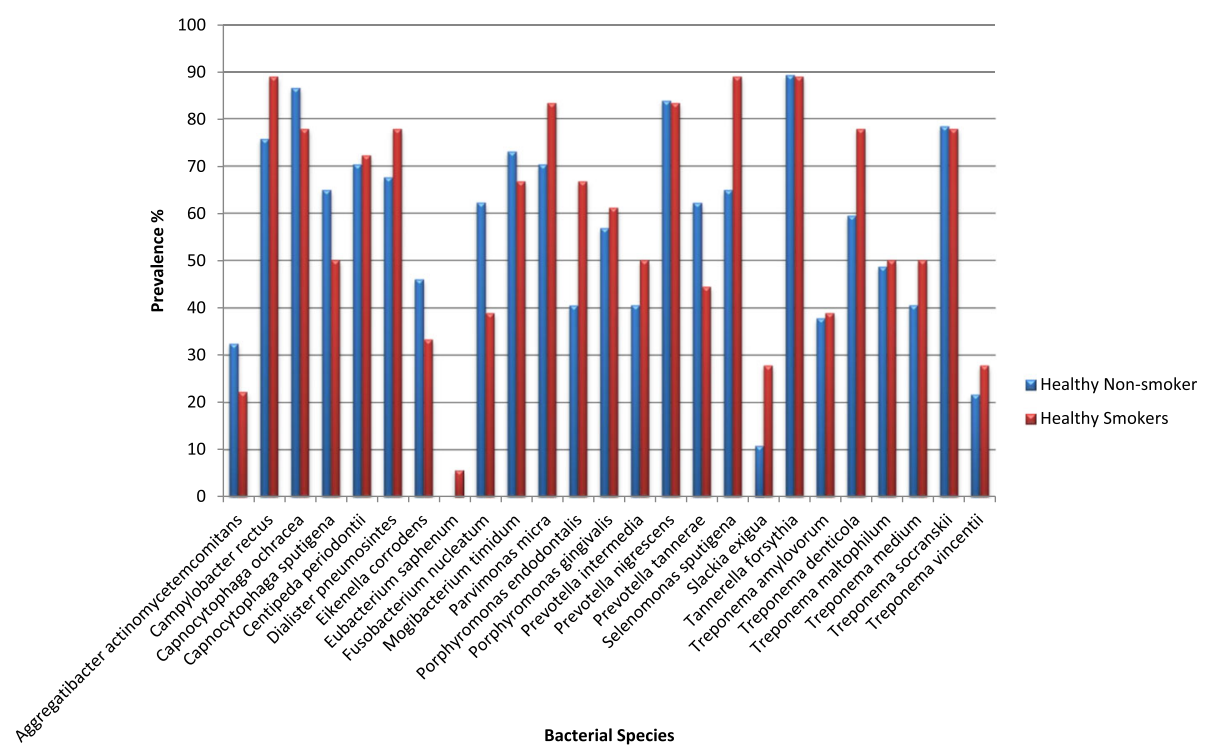

Fig. 1 Prevalence of bacterial species in healthy smokers and healthy non-smokers

Table 2 Odds of having each bacterium detected in plaque samples of healthy smokers compared to healthy non-smokers

\begin{tabular}{|c|c|c|c|c|}
\hline Bacterial species & Crude OR $(95 \% \mathrm{Cl})$ & P & Adjusted $^{\text {a }}$ OR $(95 \% \mathrm{Cl})$ & $P$-value \\
\hline Aggregatibacter actinomycetemcomitans & $0.57(0.2-2.1)$ & 0.40 & $0.76(0.1-4.1)$ & 0.74 \\
\hline Campylobacter rectus & $2.67(0.5-13.9)$ & 0.25 & $5.62(0.4-73.3)$ & 0.19 \\
\hline Capnocytophaga ochracea & $0.57(0.1-2.4)$ & 0.44 & $0.32(0.1-2.4)$ & 0.26 \\
\hline Capnocytophaga sputigena & $0.57(0.2-1.8)$ & 0.33 & $0.41(0.1-2.3)$ & 0.31 \\
\hline Centipeda periodontii & $1.14(0.3-4.0)$ & 0.83 & $0.60(0.1-3.8)$ & 0.58 \\
\hline Dialister pneumosintes & $1.75(0.5-6.5)$ & 0.40 & $2.10(0.3-14.0)$ & 0.44 \\
\hline Eikenella corrodens & $0.56(0.2-1.8)$ & 0.33 & $0.35(0.1-1.8)$ & 0.21 \\
\hline Eubacterium saphenum & - & - & - & - \\
\hline Fusobacterium nucleatum & $0.36(0.1-1.2)$ & 0.09 & $0.57(0.1-2.7)$ & 0.48 \\
\hline Mogibacterium timidum & $0.67(0.2-2.3)$ & 0.52 & $0.41(0.1-3.0)$ & 0.38 \\
\hline Parvimonas micra & $2.20(0.6-9.2)$ & 0.28 & $3.22(0.2-48.8)$ & 0.40 \\
\hline Porphyromonas endodontalis & $0.25(0.0-2.3)$ & 0.22 & $1.54(0.3-7.3)$ & 0.58 \\
\hline Porphyromonas gingivalis & $1.26(0.4-4.0)$ & 0.70 & $4.37(0.7-26.5)$ & 0.11 \\
\hline Prevotella intermedia & $1.40(0.5-4.4)$ & 0.56 & $3.95(0.6-24.1)$ & 0.14 \\
\hline Prevotella nigrescens & $0.14(0.0-1.1)$ & 0.06 & $0.31(0.0-4.7)$ & 0.40 \\
\hline Prevotella tannerae & $0.51(0.2-1.6)$ & 0.25 & $0.41(0.1-2.1)$ & 0.28 \\
\hline Selenomonas sputigena & $4.52(0.9-22.8)$ & 0.07 & $6.62(0.9-50.5)$ & 0.07 \\
\hline Slackia exigua & $3.08(0.7-13.3)$ & 0.13 & $10.1(0.7-146.1)$ & 0.09 \\
\hline Tannerella forsythia & $1.00(0.2-6.1)$ & 1.00 & $2.68(0.2-29.9)$ & 0.42 \\
\hline Treponema amylovorum & $6.05(1.1-34.4)$ & 0.04 & $4.38(0.5-33.1)$ & 0.15 \\
\hline Treponema denticola & $2.50(0.7-9.1)$ & 0.17 & $1.87(0.3-12.4)$ & 0.51 \\
\hline Treponema maltophilum & $1.12(0.4-3.5)$ & 0.85 & $1.26(0.2-6.8)$ & 0.79 \\
\hline Treponema medium & $1.57(0.5-4.9)$ & 0.44 & $1.1(0.2-5.6)$ & 0.91 \\
\hline Treponema socranskii & $1.00(0.3-3.9)$ & 1.00 & $0.92(0.1-6.7)$ & 0.93 \\
\hline Treponema vincentii & $8.29(0.7-104.9)$ & 0.10 & $1.41(0.2-9.2)$ & 0.72 \\
\hline
\end{tabular}


patients. Smoking was the dependent variable and independent variables (covariates) were: age, gender, education level, PPD and type of bacteria. Gender, education level and type of bacteria were set as categorical variables, while age and PPD were set as continuous variables (default). Both crude and OR corrected for age, gender, education level and PPD $\left(\mathrm{OR}_{\mathrm{adj}}\right)$ were presented. All statistical analyses were conducted using IBM SPSS 24 (SPSS Inc., Chicago, USA). The adjusted OR ( $\left.\mathrm{OR}_{\mathrm{adj}}\right)$ was adopted for interpreting the results and a $p$-value $\leq 0.05$ was considered to be statistically significant. SPSS could not calculate the OR for the bacteria if the prevalence was $100 \%$ or $0 \%$ in any of the compared groups; in that case, only the $p$-value for $\chi^{2}$ analysis was shown. A power calculation was conducted to determine the statistical power of our samples to detect an association using the $G^{*}$ Power program [20]. The input parameters were: effect size $=0.3$ (small size $=0.1$, medium size $=$ 0.3 ), statistical significance level $\alpha=0.05$ and two tailed.

\section{Results}

The sociodemographic and clinical data for the participants are summarized in Table 1.

In our sample set, a significant difference in gender was observed between smokers and non-smokers in the two groups, where males dominated the smokers groups $(p<0.0001)$. The PPD was significantly higher among the healthy non-smokers group compared to healthy smokers. No significant difference was observed in the oral hygiene habits between the four investigated groups (data not shown).
The frequency of bacteria and the odds of having each of the 25 bacteria among healthy smokers compared to healthy non-smokers are presented in Fig. 1 and Table 2, respectively. Both crude and adjusted regression analyses are presented in Table 2. The odds of having 15 bacteria was increased in healthy smokers compared to healthy non-smokers, and the highest increases were detected in Slackia exigua, Selenomonas sputigena, and Campylobacter rectus $\left(\mathrm{OR}_{\mathrm{adj}}=10.1,6.62\right.$ and 5.62, respectively). The odds of having eight bacteria was decreased among healthy smokers, and the decrease was mostly noted in Prevotella nigrescens, Capnocytophaga ochracea, and Eikenella corrodens $\left(\mathrm{OR}_{\mathrm{adj}}=0.31,0.32\right.$ and 0.35 , respectively $)$. None of these differences were statistically significant. Eubacterium saphenum was not present among nonsmokers.

Within the CP group, when smokers were compared to non-smokers, the prevalence of six bacteria was increased among smokers (Fig. 2). When correcting for confounders, Treponema amylovorum, Treponema medium, Slackia exigua and Treponema vincentii had the highest odds ratios $\left(\mathrm{OR}_{\mathrm{adj}}=20.7,7.97,6.37\right.$ and 5.37, respectively) and the increase in Treponema amylovorum was statistically significant $(p=0.05)$ (Table 3$)$. Treponema denticola, Treponema socranskii and Tannerella forsythia were present in all $\mathrm{CP}$ smokers. The remaining bacteria were decreased among $\mathrm{CP}$ smokers (Table 3).

Power calculations revealed that the sample set had 62.9 and $48.1 \%$ power to detect an association for healthy and $\mathrm{CP}$ groups, respectively, when the significance level was set at 0.05 .

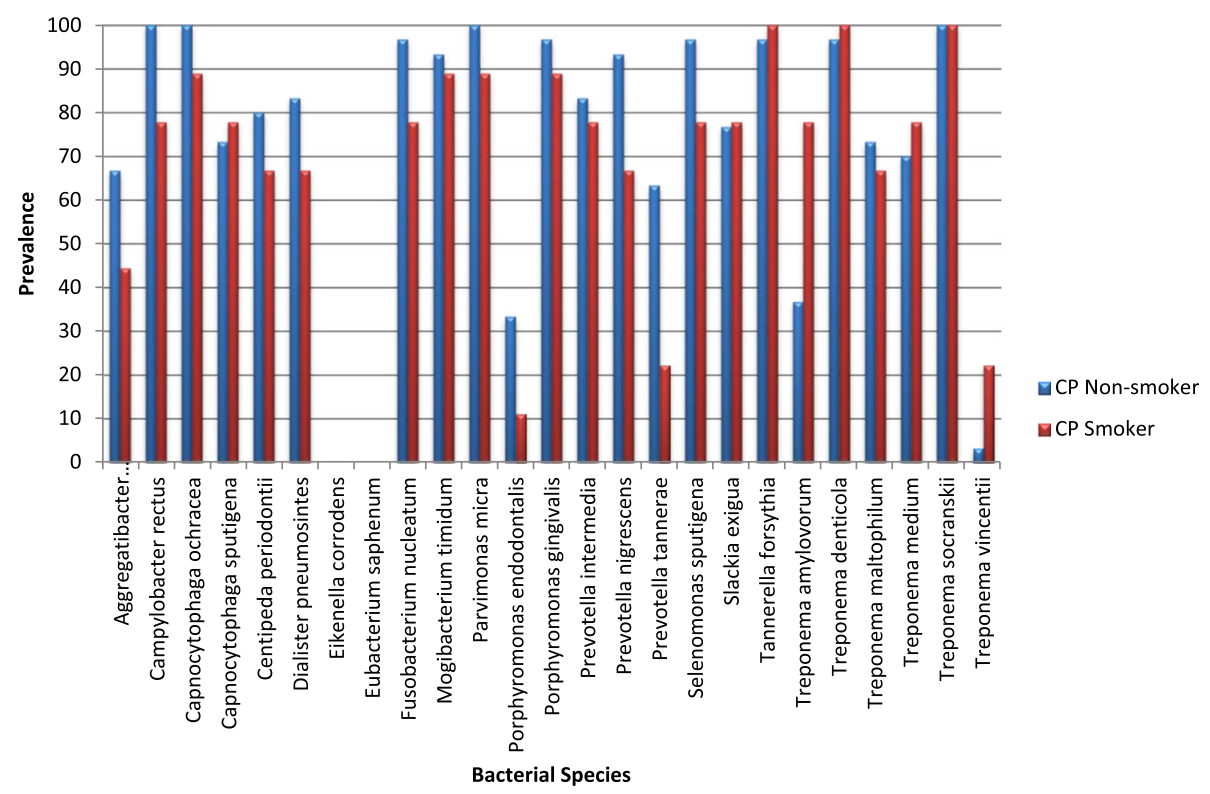

Fig. 2 Prevalence of bacterial species in CP patients who were smokers or non-smokers 
Table 3 Odds of having each bacterium detected in plaque samples of CP smokers compared to CP non-smokers

\begin{tabular}{|c|c|c|c|c|}
\hline Bacterial species & Crude OR $(95 \% \mathrm{Cl})$ & $P$-value & Adjusted $^{\mathrm{a}}$ OR $(95 \% \mathrm{Cl})$ & $P$-value \\
\hline Aggregatibacter actinomycetemcomitans & $0.40(0.1-1.8)$ & 0.24 & $0.53(0.07-4.4)$ & 0.57 \\
\hline Campylobacter rectus & - & & - & $0.01^{*}$ \\
\hline Capnocytophaga ochracea & - & & - & $0.06^{*}$ \\
\hline Capnocytophaga sputigena & $1.27(0.2-7.5)$ & 0.79 & $4.8(0.2-108.1)$ & 0.32 \\
\hline Centipeda periodontii & $0.50(0.1-2.6)$ & 0.41 & $0.88(0.1-8.4)$ & 0.91 \\
\hline Dialister pneumosintes & $0.40(0.1-2.2)$ & 0.29 & $0.76(0.07-8.2)$ & 0.82 \\
\hline Eikenella corrodens & - & & - & - \\
\hline Eubacterium saphenum & - & & - & - \\
\hline Fusobacterium nucleatum & $0.12(0.0-1.5)$ & 0.10 & $0.52(0.0-44.3)$ & 0.77 \\
\hline Mogibacterium timidum & $0.57(0.1-7.1)$ & 0.66 & $0.09(0.0-2.0)$ & 0.13 \\
\hline Parvimonas micra & - & & - & $0.06^{*}$ \\
\hline Porphyromonas endodontalis & $0.25(0.0-2.3)$ & 0.22 & $0.25(0.02-3.5)$ & 0.31 \\
\hline Porphyromonas gingivalis & $0.28(0.0-4.9)$ & 0.38 & $0.19(0.01-5.3)$ & 0.32 \\
\hline Prevotella intermedia & $0.70(0.1-4.4)$ & 0.70 & $0.78(0.05-13.3)$ & 0.87 \\
\hline Prevotella nigrescens & $0.14(0.0-1.0)$ & 0.06 & $0.66(0.04-10.3)$ & 0.77 \\
\hline Prevotella tannerae & $0.17(0.0-0.9)$ & 0.04 & $0.57(0.1-5.7)$ & 0.63 \\
\hline Selenomonas sputigena & $0.12(0.0-1.5)$ & 0.10 & $0.34(0.0-46.5)$ & 0.66 \\
\hline Slackia exigua & $1.07(0.2-6.4)$ & 0.95 & $6.37(0.3-146.1)$ & 0.25 \\
\hline Tannerella forsythia & - & & - & ${ }^{*} 0.58$ \\
\hline Treponema amylovorum & $6.05(1.1-34.4)$ & 0.04 & $20.7(0.9-466.0)$ & 0.05 \\
\hline Treponema denticola & - & & - & ${ }^{*} 0.58$ \\
\hline Treponema maltophilum & $0.73(0.2-3.6)$ & 0.70 & $0.79(0.1-7.2)$ & 0.84 \\
\hline Treponema medium & $1.50(0.3-8.7)$ & 0.65 & $7.97(0.4-67.1)$ & 0.23 \\
\hline Treponema socranskii & - & & - & $1.00^{*}$ \\
\hline Treponema vincentii & $8.29(0.7-104.9)$ & 0.001 & $5.37(0.2-151.8)$ & 0.32 \\
\hline
\end{tabular}

* $P$ value based on $X^{2}$ analysis

${ }^{a}$ Adjusted for gender and education level

Significant $P$ values $\leq 0.05$ are shown in bold

\section{Discussion}

This study reports the effect of smoking on the bacterial profile of healthy and CP subjects by comparing the bacterial profile of 25 bacterial species among smokers and non-smokers. These particular bacterial species were analyzed because there is previous evidence of their association with periodontal diseases [19, 21]. Among healthy individuals, the bacteria present among smokers differ from those present among non-smokers although both are periodontitis-free groups $(\mathrm{CAL}=0.00)$. A moderate increase in the red complex bacteria was observed among smokers compared to non-smokers, which agrees with previously reported results [15]. However, smoking was responsible for increasing the prevalence of other periodontopathogenic bacteria in subjects with healthy gingiva that were also prevalent in CP patients. After ruling out the effects of other confounding factors, smoking was responsible for increasing the prevalence of Slackia exigua, Selenomonas sputigena, and Campylobacter rectus by $910 \%, 562 \%$, and $462 \%$ times, respectively. Furthermore, smoking was responsible for decreasing the prevalence of bacteria that were considered to be less periodontopathogenic, for instance, Eikenella corrodens was $65 \%$ less likely to be present among healthy smokers. These findings indicate that smoking is responsible for the depletion of beneficial bacteria and increasing the abundance of periodontopathogenic bacteria among healthy individuals.

When comparing the bacterial profiles of smoker and non-smoker CP patients, an unexpected observation was the increased prevalence and the odds of having many of the investigated bacterial species among the non-smokers. Exceptions were limited to Treponema species and Slackia exigua which were increased among CP smokers. Previous reports concluded that smoking is responsible for enriching the subgingival microbiota with pathogenic species $[14,22]$. This effect was supported by more recent studies conducted on CP patients, which concluded that smoking 
has a detrimental impact on the periodontal status and the microbial profile $[11,23]$. This was further supported by a longitudinal study investigating the effect on bacteria of smoking cessation after 6 and 12 months among CP patients [24]. Our results support the view that smoking affects the subgingival microbiota in CP patients and that it is responsible for the increase in the Treponema species and Slackia exigua. They also suggest that, in non-smoker $\mathrm{CP}$ patients, bacteria tend to play a more crucial role in pathogenesis, where a larger number of bacterial species will be involved in constructing the subgingival plaque, while in smoker CP patients, smoking is more likely to contribute to the disease by inducing changes within gingival tissues and the gingival sulcus. Smoking has been reported to affect the immune response against bacteria [25] by lowering gingival crevicular fluid (GCF) volume $[26,27]$ or by affecting the host antibody response [28], through reducing sera immunoglobulin G antibody titers against the subgingival bacteria [10].

When looking at the whole sample set, smoking had two distinct effects on subgingival bacteria: some bacteria were more prevalent among smokers as observed with Tannerella forsythia, Treponema denticola and Treponema medium, while other bacteria were less prevalent among smokers as observed with Aggregatibacter actinomycetemcomitans, Fusobacterium nucleatum, Prevotella tannerae, Capnocytophaga ochracea and Mogibacterium timidum. Based on these observations, smoking might induce changes in the oral and gingival ecosystem that make the environment more favorable for some bacterial species to grow, while for others, these changes make the environment less favorable for growth.

Gender was found to be significantly different between smokers and non-smokers of both groups. This was mainly attributed to the fact that the prevalence of smoking is much higher in males compared to females in the Jordanian population $[29,30]$. The prevalence of smoking in Jordanian men is reported to be in the range of $56.9-62 \%$ compared to $11.0-11.4 \%$ in women [29, 30]. The effect of gender on the subgingival bacterial flora is controversial; several studies conducted on periodontitis patients have reported a difference in the bacterial profile between males and females [31, 32], while other studies have reported that gender has no effect on the subgingival bacterial profile in CP patients or in healthy controls $[33,34]$. The PPD was significantly higher in healthy non-smokers compared to smokers; this increase is most likely related to increased age among the nonsmokers.

This study investigated the effect of smoking on the prevalence of bacterial species; however, no changes in the serotype induced by smoking could be determined. Furthermore, no quantitative judgments on the amount of bacteria could be made as this requires using a realtime PCR technique, which was not available to us. An effect of smoking on the immune response [10, 25-28] could not be ruled out, and this would provide another mechanism of action in inducing periodontal disease. Finally, although differences in the bacterial profile could be detected in this sample set, only the increase in Treponema amylovorum in CP smokers was statistically significant $(p=0.05)$; other differences were not statistically significant $(p>0.05)$ due to limited power related to the small sample number, which is one of the limitations of the study; hence, conclusions based on these results should be interpreted with caution.

\section{Conclusions}

Smoking affects the subgingival bacterial profile in healthy individuals and is responsible for the depletion of beneficial bacteria and the increase in periodontopathogenic bacteria. In the $\mathrm{CP}$ patient group, our study suggests that subgingival bacteria (particularly Treponema species) might make a more substantial contribution in the etiology of $\mathrm{CP}$ among non-smokers. Further studies using a larger sample set and more sensitive and quantitative techniques (such as real-time PCR) are needed to enhance our understanding of the exact effect of smoking on subgingival biofilm.

\section{Additional file}

Additional file 1: Target Bacteria and Their Species-Specific Primers. A table including names of bacteria investigated and the species-specific primers (forward and reverse) used for the PCR. (DOCX $16 \mathrm{~kb}$ )

\section{Abbreviations}

bp: Base pair; CAL: Clinical attachment loss; CP: Chronic periodontitis; DTC: Dental teaching centre; F: Forward; g: Relative centrifugal force; GCF: Gingival crevicular fluid; Gl: Gingival index; IRB: Institutional Research Board; JUST: Jordan University of Science and Technology; min: Minute; OR: Odds ratio; OR adj: Adjusted odds ratio; PBS: Phosphate-buffered saline; PCR: Polymerase chain reaction; PI: Plaque index; PPD: Periodontal pocket depth; R: Reverse; rRNA: Ribosomal ribonucleic acid; s: Seconds; SD: Standard deviation.

\section{Acknowledgements \\ Not applicable.}

\section{Funding}

This study was fully funded by the Deanship of Scientific Research, Jordan University of Science and Technology (JUST), Grant number 84/2008.

Availability of data and materials

The data will not be made available in order to protect the participants' identity.

\section{Authors' contributions}

JK was responsible for the study design, preparing the questionnaires used for the study, statistical analysis and writing the paper. RA was responsible for evaluating the patients for a final diagnosis, collecting plaque samples and preparing the questionnaires used in the study. NAM was responsible for conducting the laboratory work including bacterial DNA extraction and PCR. MT commented on the methodology of the study and was responsible for editing the paper and final drafting. All authors read and approved the final manuscript. 


\section{Competing interests}

The authors declare that they have no competing interests.

\section{Consent for publication}

Not applicable.

\section{Ethics approval and consent to participate}

The study was independently reviewed and approved by the Institutional Research Board (IRB) of Jordan University of Science and Technology (JUST). Written consent was obtained before interview and after explaining the study purposes, methodology and possible future publication of clinical datasets according to the Declaration of Helsinki.

\section{Publisher's Note}

Springer Nature remains neutral with regard to jurisdictional claims in published maps and institutional affiliations.

\section{Author details}

'Department of Oral Medicine \& Oral Surgery, Faculty of Dentistry, Jordan University of Science \& Technology, Irbid, Jordan. ${ }^{2}$ Department of Preventive Dentistry, Faculty of Dentistry, Jordan University of Science and Technology, Irbid, Jordan. ${ }^{3}$ Department of Medical Sciences, Uppsala University, Uppsala, Sweden. ${ }^{4}$ Unit of Oral and Maxillofacial Medicine and Surgery, The University of Sheffield, School of Clinical Dentistry, Sheffield, UK.

Received: 16 October 2016 Accepted: 3 March 2017

Published online: 21 March 2017

\section{References}

1. Hassell TM, Harris EL. Genetic influences in caries and periodontal diseases. Crit Rev Oral Biol Med. 1995:6:319-42.

2. Filoche S, Wong L, Sissons CH. Oral biofilms: emerging concepts in microbial ecology. J Dent Res. 2010;89:8-18.

3. Stabholz A, Soskolne WA, Shapira L. Genetic and environmental risk factors for chronic periodontitis and aggressive periodontitis. Periodontol 2000. 2010;53:138-53.

4. Linden GJ, Mullally BH. Cigarette smoking and periodontal destruction in young adults. J Periodontol. 1994;65:718-23.

5. Tomar SL, Asma S. Smoking-attributable periodontitis in the United States: findings from NHANES III. National Health and Nutrition Examination Survey. J Periodontol. 2000;71:743-51.

6. Bergström J, Eliasson S, Dock J. Exposure to tobacco smoking and periodontal health. J Clin Periodontol. 2000;27:61-8.

7. Jette AM, Feldman HA, Tennstedt SL. Tobacco use: a modifiable risk factor for dental disease among the elderly. Am J Public Health. 1993;83:1271-6.

8. Haffajee AD, Socransky SS. Relationship of cigarette smoking to the subgingival microbiota. J Clin Periodontol. 2001;28:377-88.

9. Boström L, Bergström J, Dahlén G, Linder LE. Smoking and subgingival microflora in periodontal disease. J Clin Periodontol. 2001;28:212-9.

10. Apatzidou DA, Riggio MP, Kinane DF. Impact of smoking on the clinical, microbiological and immunological parameters of adult patients with periodontitis. J Clin Periodontol. 2005;32:973-83.

11. Gomes SC, Piccinin FB, Oppermann RV, Susin C, Nonnenmacher Cl, Mutters R, et al. Periodontal status in smokers and never-smokers: clinical findings and real-time polymerase chain reaction quantification of putative periodontal pathogens. J Periodontol. 2006;77:1483-90.

12. Kamma JJ, Nakou M, Baehni PC. Clinical and microbiological characteristics of smokers with early onset periodontitis. J Periodontal Res. 1999;34:25-33.

13. Eggert FM, McLeod MH, Flowerdew G. Effects of smoking and treatment status on periodontal bacteria: evidence that smoking influences control of periodontal bacteria at the mucosal surface of the gingival crevice. Periodontol. 2001;72:1210-20.

14. Van Winkelhoff AJ, Bosch-Tijhof CJ, Winkel EG, van der Reijden WA. Smoking affects the subgingival microflora in periodontitis. J Periodontol. 2001;72:666-71

15. Shiloah J, Patters MR, Waring MB. The prevalence of pathogenic periodontal microflora in healthy young adult smokers. J Periodontol. 2000;71:562-7.

16. Armitage GC. Development of a classification system for periodontal disease and conditions. Ann Periodontol. 1999:4:1-6.

17. Löe $H$. The gingival index, the plaque index and the retention index system. J Periodontol. 1967;38:610-6.
18. Lane DJ. 16S/23S rRNA sequencing. In: Stackebrandt E, Goodfellow M, editors. Nucleic acid techniques in bacterial systematics. Chichester: John Wiley and Sons; 1991. p. 115-75.

19. Mayanagi G, Sato T, Shimauchi H, Takahashi N. Detection frequency of periodontitis-associated bacteria by polymerase chain reaction in subgingival and supragingival plaque of periodontitis and healthy subjects. Oral Microbiol Immunol. 2004;19:379-85.

20. Faul F, Erdfelder E, Lang AG, Buchner A. G*Power 3: A flexible statistical power analysis program for the social, behavioral, and biomedical sciences. Behav Res Methods. 2007;39:175-91.

21. Flemmig TF. Periodontitis. Ann Periodontol. 1999:4:32-8.

22. Zambon JJ, Grossi SG, Machtei EE, Ho AW, Dunford R, Genco RJ. Cigarette smoking increases the risk for subgingival infection with periodontal pathogens. J Periodontol. 1996;67:1050-4.

23. Shchipkova AY, Nagaraja HN, Kumar PS. Subgingival microbial profiles of smokers with periodontitis. J Dent Res. 2010;89:1247-53.

24. Fullmer SC, Preshaw PM, Heasman PA, Kumar PS. Smoking cessation alters subgingival microbial recolonization. J Dent Res. 2009;88:524-8.

25. Palmer RM, Wilson RF, Hasan AS, Scott DA. Mechanisms of action of environmental factors - tobacco smoking. J Clin Periodontol. 2005:32:180-95.

26. Holmes LG. Effects of smoking and/or vitamin C on crevicular fluid flow in clinically healthy gingiva. Quintessence Int. 1990;21:191-5.

27. Persson L, Bergström J, Gustafsson A, Asman B. Tobacco smoking and gingival neutrophil activity in young adults. J Clin Periodontol. 1999:26:9-13.

28. Haber J. Cigarette smoking: a major risk factor for periodontitis. Compendium. 1994;15:1002-14

29. Khader YS, Alsadi AA. Smoking habits among university students in Jordan: prevalence and associated factors. East Mediterr Health J. 2008:14:897-904.

30. Khabour OF, Alzoubi KH, Eissenberg T, Mehrotra P, Azab M, Carroll MV, et al. Waterpipe tobacco and cigarette smoking among university students in Jordan. Int J Tuberc Lung Dis. 2012:16:986-92.

31. Slots J, Feik D, Rams TE. Age and sex relationships of superinfecting microorganisms in periodontitis patients. Oral Microbiol Immunol. 1990;5:305-8

32. Umeda M, Chen C, Bakker I, Contreras A, Morrison JL, Slots J. Risk indicators for harboring periodontal pathogens. J Periodontol. 1998;69:1111-8.

33. Schenkein HA, Burmeister JA, Koertge TE, Brooks CN, Best AM, Moore LV, et al. The influence of race and gender on periodontal microflora. J Periodontol. 1993;64:292-6.

34. Fischer CC, Persson RE, Persson GR. Influence of the menstrual cycle on the oral microbial flora in women: a case-control study including men as control subjects. J Periodontol. 2008;79:1966-73.

\section{Submit your next manuscript to BioMed Central} and we will help you at every step:

- We accept pre-submission inquiries

- Our selector tool helps you to find the most relevant journal

- We provide round the clock customer support

- Convenient online submission

- Thorough peer review

- Inclusion in PubMed and all major indexing services

- Maximum visibility for your research

Submit your manuscript at www.biomedcentral.com/submit
Biomed Central 